\title{
Professionalism in Wildlife Management: The Case of Gallifoms Releases in Hellas
}

\author{
Christos K. Sokos ${ }^{1}$ Periklis K. Birtsas ${ }^{1,2}$, Konstantinos G. Papaspyropoulos, \\ Carlos Sánchez-García ${ }^{3}$ \\ ${ }^{1}$ Research Division, Hunting Federation of Macedonia and Thrace, Ethnikis Antistasis, \\ Thessaloniki, Hellas (Greece) \\ ${ }^{2}$ Wildlife Laboratory, Department of Forestry and Management of Natural Environment, Technological \\ Education Institute of Thessaly, Karditsa, Hellas (Greece) \\ ${ }^{3}$ The Game \& Wildlife Conservation Trust, Burgate Manor, Fordingbridge, UK \\ Email:sokos@vet.uth.gr
}

Received 13 January 2016; accepted 1 February 2016; published 4 February 2016

Copyright (C) 2016 by authors and Scientific Research Publishing Inc.

This work is licensed under the Creative Commons Attribution International License (CC BY). http://creativecommons.org/licenses/by/4.0/

(c) (i) Open Access

\section{Abstract}

Hunting organizations in cooperation with the Forest Service release thousands of artificially reared pheasants and partridges in Hellas (Greece). To evaluate the effectiveness of this practice a questionnaire was applied to hunting wardens of four hunting federations in 2002 and one in 2011. Moreover data were obtained from the wildlife managers of one federation from 2009 to 2014. The release of hybrid pheasants and chukar partridges was conducted by the majority of local hunting clubs (H.C.). Most hunting wardens and wildlife managers stated that even during the most successful release only a small percentage $(1 \%-10 \%)$ of released birds can survive for more than three months and usually none of the released birds or a few achieve to rear chicks. However, repeated releases led to the establishment of small groups of birds in some areas, but without a serious benefit for hunting activity. In case of releases for hunting purposes (put and take), the respondents said that the majority $(90 \%)$ of galliforms were killed by predators or hunters within a few days after release, and that only few (18 - 25) hunters harvested the survived birds. Until 2009, in northern and central mainland Hellas, the minimum cost per bird entering to the hunter's bag was $143 €$. That amount is estimated to be $33.47 €$ in islands and after 2009 in mainland. In conclusion, the professionalism in galliforms releases should get improved with appropriate legal decisions and organization structures.

\section{Keywords}

Survival, Reproduction, "Put and Take”, Hunting, Population Establishment 


\section{Introduction}

In Hellas, quarry belongs to the hunter and not to the landowner, while the hunting right is acquired by the issue of a hunting license every year. In recent decades the hunting demand in Hellas has increased, while the availability of quarry and quality of hunting have been reduced owing to several factors such as habitat degradation and inappropriate hunting regulations (Birtsas et al., 2009). To mitigate this problem, hunters finance, through hunting licenses, their organizations and the Green Fund of the Ministry of Environment for the development of hunting and other actions for the environment. The Hellenic government does not respond efficiently to this legal requirement, while the main and immediate measure which is taken for the hunting development is the rearing and releasing of galliforms (or gamebirds) (Birtsas et al., 2009).

Galliforms' release in the wild consists of a common practice in Europe (Viñuela \& Arroyo, 2002). Galliforms are normally released into the wild for the following aims: 1 ) conservation or increase of viable populations, 2) establishing populations (introduction, re-introduction) and augmenting threatened (endangered) populations, 3) providing stock for shooting, with releases just before and during the hunting season with direct harvest, a practice often known as "put and take", and 4) the training of hunting dogs (Sokos et al., 2008). The released birds can come either from the translocation of wild individuals or rearing. In galliforms rearing, various techniques are applied for eggs incubation, chick raising and release in nature (Sokos et al., 2008).

In Hellas, cases of successful establishment of galliforms after their release by man are tracked even in prehistoric times (Masseti, 1997). More serious releasing efforts have been conducted since 1956 with the establishment of state farms (Pringale, 1972). Nowadays, there are about ten state farms rearing galliforms using artificial rearing (incubators and brooders). The annual production in 2003 was 85,000 pheasants (mainly hybrids between subspecies of Phasianus colchicus and few thousands of black-necked pheasants Phasianus colchicus colchicus with genetic introgression), 60 - 70,000 chukar partridges (Alectoris chukar cypriotes and several crossings and maybe hybrids with rock partridge Alectoris graeca), 4000 Japanese quails (Coturnix coturnix japonica) and few hundreds of rock partridges (Anestis, 2003, personal communication, Ministry of Agriculture). According to the 2008 Annual Activity Report of Forest Services, the cost of galliforms production from state farms exceeds the 1,000,000 €/year. Since 2010 the production has been significantly reduced to about one half, but no relevant data exist (Traiforos, 2011; Nikoletopoulos, 2016; personal communications with the Ministry of the Environment). Moreover some hunting organizations maintain farms, while others are supplied birds by private farms which also apply artificial breeding. The private farms except the above species rear grey partridge (Perdix perdix) and rock partridge.

Until 2009 the galliforms had to be released only in areas where hunting was prohibited. An exception was the islands of the Aegean Sea, where from the $1^{\text {st }}$ of January to $31^{\text {st }}$ of August it was permitted to release a percentage of $50 \%$ of the number of released chukar partridges in hunting areas. Since 2009 releases can be conducted in hunting areas for hunting, but releasing must be conducted at least 30 days prior of the opening of the hunting season (Ministerial Decision 98161/4136/09.29.2008). Additionally, the above mentioned Decision is a first positive step to decrease the serious genetic introgression caused by uncontrolled breeding and galliforms' releases (e.g. Barbanera et al., 2007; Barilani et al., 2007). Therefore, in recent years it is not allowed to release hybrid pheasants in Thrace (in northeast Hellas) and chukar partridges in mainland Hellas (except Thrace), a genetic certification of birds is needed and a study should be written by a wildlife manager before a release approved by Forest Service.

In this study, we aimed to evaluate the effectiveness of galliforms' release practices, using information provided by hunting wardens and wildlife managers of hunting organizations in the years 2002, 2011 and 2014. Moreover, an ecological and economical evaluation of the practice was carried out. The continuous survey of releases helps to examine the efficiency of the responsible agencies for improvements on the practice and finally on the assessment of professionalism that was applied.

\section{Methods}

The present study used data from the hunting regions of Macedonia and Thrace, Epirus, Thessaly and North Aegean for 2002 and to Macedonia and Thrace for 2011 and 2014. The hunting wardens of hunting organizations were actively involved in the releases and the monitoring of released birds. Therefore, along the training seminars for hunting wardens, a special designed questionnaire for galliforms' releases was distributed and completed by each hunting warden. The research was performed at the level of the local hunting club (H.C.) 
which was represented by at least one hunting warden. Where the H.C. was represented by two or more hunting wardens, the median of their opinions was taken into account. In 2011, nine years later, the same hunting wardens of Macedonia and Thrace were asked again but in 2014 the study was based on the wildlife managers' answers.

From 2009 the wildlife managers, as scientific collaborators of hunting federations, are responsible for the release planning. Consequently the wildlife managers of Macedonia and Thrace were also asked about the 108 releases of galliforms that they planned and applied from 2009 to 2014. The questions were referred to: 1) the aim of release (population establishment or harvest), 2) in case of establishment which is the approximately mean number of birds during spring and harvested birds the last three years, 3) in case of release for harvest, in how many days the majority of birds was killed (about 90\%) after the day of release from predators, hunters and other reasons and how many hunters harvested the majority of released and survived birds.

From the questionnaires, binary and nominal variables were created depending on the respondents' answers. Non parametric statistical analysis was used to analyze these variables. McNemar test was used to compare the areas of Macedonia and Thrace in order to be shown if in the area there was a statistical difference between the years 2002 and 2011. McNemar test is used in nominal and binary variables if the samples are dependent (Hair, et al., 2006). Additionally for the case of more than two independent samples, the non parametric test of Kruskal-Wallis one-way analysis of variance was used (One-Way ANOVA) (H test), and for the case of two independent samples the Mann-Whitney U test was used (Hair et al., 2006). Firstly, the comparisons were relevant to the responses of the hunting wardens if galliforms releases take place in their region (Thrace, Macedonia, Thessaly, Epirus, Aegean). Then comparisons were made for the assessments of hunting wardens about the success of releases and for whether galliform populations were established after release. For these comparisons, the statistical package SPSS 22.0 at significance level a = 5\% has been used (Gray \& Kinnear, 2012).

\section{Results}

\subsection{Records of Releases}

The study was carried out in 81 H.C. in 2002 and 55 in 2011 (Table 1). The H.C. release mainly pheasant hybrids (61.9\% of releases). In Macedonia and Thrace there were no differences between 2002 and 2011 for the species continued to be released (exact $p>1$ ). In 2002 chukar partridges were released in all regions. Multivariate analysis showed that there were differences between regions (Kruskal-Wallis asymptotic $\mathrm{p}=0.038, \mathrm{df}=4$ ). Post hoc tests of areas showed that only between Thrace and Thessaly there was a significant difference (KruskalWallis asymptotic $p=0.043$ ) due to the less releases of pheasants in Thessaly.

\subsection{Survival and Raising Chicks after Release}

Most hunting wardens said that even in the most successful release, a small percentage (1\% - 10\%) of released birds survived longer than three months (Table 2), and an even lower proportion of released galliforms were reproduced in the wild (Table 3). The Mann-Whitney $\mathrm{U}$ test showed that there was no difference among regions (asymptotic $p>0.05$ ).

\subsection{Establishment of Galliforms Populations}

Table 4 shows that in a total of 141 H.C. in which releases took place in both periods, in fewer than half (59) a

Table 1. Ratio of hunting clubs which made at least one release with galliforms in the last five years in their area.

\begin{tabular}{ccccccccc}
\hline \multirow{2}{*}{ Species } & \multicolumn{2}{c}{ Thrace } & \multicolumn{2}{c}{ Macedonia } & Epirus & \multicolumn{2}{c}{ Thessaly } & N. Aegean \\
\cline { 2 - 8 } & 2002 & 2011 & 2002 & 2011 & 2002 & 2002 & 2002 \\
\hline Black-necked pheasants & $6 / 9$ & $7 / 10$ & $0 / 42$ & $1 / 45$ & $0 / 7$ & $0 / 9$ & $0 / 14$ \\
Pheasants hybrids & $5 / 9$ & $0 / 10$ & $28 / 42$ & $31 / 45$ & $4 / 7$ & $2 / 9$ & $8 / 14$ \\
Chukar partridges & $8 / 9$ & $6 / 10$ & $19 / 42$ & $0 / 45$ & $4 / 7$ & $7 / 9$ & $3 / 14$ \\
Grey partridges & $0 / 9$ & $0 / 10$ & $0 / 42$ & $2 / 45$ & $0 / 7$ & $0 / 9$ & $0 / 14$ \\
Total & $8 / 9$ & $7 / 10$ & $31 / 42$ & $32 / 45$ & $4 / 7$ & $7 / 9$ & $8 / 14$ \\
\hline
\end{tabular}


Table 2. Number of hunting wardens that answer whether in the most successful release of the last five years, there were birds which survived more than three months in accordance with personal observations-estimations and information from hunters.

\begin{tabular}{cccccc}
\hline Species & None & $1 \%-10 \%$ & $11 \%-50 \%$ & $50 \%-$ & Do not know \\
\hline Black-necked pheasants & 2 & 4 & 3 & 0 & 8 \\
Pheasants hybrids & 17 & 42 & 15 & 5 & 15 \\
Chukar partridges & 10 & 45 & 16 & 6 & 11 \\
Total & 29 & 91 & 34 & & 39 \\
\hline
\end{tabular}

Table 3. Number of hunting wardens that answer whether in the most successful release of the last five years, there were birds which reared chicks in accordance with personal observations-estimations and information from hunters.

\begin{tabular}{cccccc}
\hline Species & None & $1 \%-10 \%$ & $11 \%-50 \%$ & $50 \%-$ & Do not know \\
\hline Black-necked pheasants & 2 & 5 & 0 & 0 & 7 \\
Pheasants hybrids & 28 & 33 & 10 & 10 & 2 \\
Chukar partridges & 16 & 40 & 20 & 7 & 25 \\
Total & 46 & 78 & 55 \\
\hline
\end{tabular}

Table 4. Ratio of hunting clubs where a number of galliforms were established after releases.

\begin{tabular}{cccccccccc}
\hline \multirow{2}{*}{ Species } & \multicolumn{2}{c}{ Thrace } & \multicolumn{2}{c}{ Macedonia } & Epirus & Thessaly & N. Aegean & Total \\
\cline { 2 - 7 } & 2002 & 2011 & 2002 & 2011 & 2002 & 2002 & 2002 & $3 / 14$ \\
Black-necked pheasants & $2 / 6$ & $1 / 7$ & $0 / 0$ & $0 / 1$ & $0 / 0$ & $0 / 0$ & $0 / 0$ & $33 / 78$ \\
Pheasants hybrids & $1 / 5$ & $0 / 0$ & $14 / 28$ & $9 / 31$ & $3 / 4$ & $1 / 2$ & $5 / 8$ & $1 / 3$ & $23 / 47$ \\
Chukar partridges & $2 / 8$ & $1 / 6$ & $7 / 19$ & $2 / 0$ & $3 / 4$ & $7 / 7$ & $0 / 0$ & $0 / 2$ \\
Grey partridges & $0 / 0$ & $0 / 0$ & $0 / 0$ & $0 / 2$ & $0 / 0$ & $0 / 0$ & $8 / 9$ & $6 / 11$ & $59 / 141$ \\
Total & $5 / 19$ & $2 / 13$ & $21 / 47$ & $11 / 34$ & $6 / 8$ & & & &
\end{tabular}

number of galliforms were established. In Macedonia it was found a significant difference for pheasant hybrids between 2002 and 2011 (exact $p=0.003, \mathrm{df}=1$ ). In 2002 among the five regions a difference was noticed for the chukar partridges (Kruskal Wallis asymptotic $p=0.008, \mathrm{df}=4$ ). These differences were detected with post hoc tests between Thrace and North Aegean $(p=0.034)$ and marginally for Macedonia and North Aegean $(\mathrm{p}=$ $0.05)$.

These established galliforms were usually small groups of 10 - 50 survived birds that did not constitute a viable population. The cases of viable population establishment were very few (\%). In Thrace, one chukar partridge population and one population of genetically introgressed pheasants in H.C. of Komotini were established successfully. In spring these populations amounted to 200 - 300 individuals, the releasing was continued to these areas and during the hunting season there were hunted about 50 - 100 birds in each area. In Macedonia populations of pheasant hybrids were established in nine areas. The largest population was in the area of H.C. of Epanomis near Thessaloniki, with a spring population of 200 hybrid pheasants (Ch. Sokos, 2008, unpublished data, Hunting Federation of Macedonia \& Thrace). In this area the pheasant releases continued until 2009 inside a prohibited area. The pheasants were dispersed outside from the refuge and during the hunting season there were hunted about 100 birds. From 2010, that the releases were stopped, the number of harvested pheasants stays constant or has increased. In the other eight areas small numbers of birds were established providing a harvest amounted to 10 - 40 hybrid pheasants each year. Also in areas of H.C. of Staurou and near the city of Thessaloniki there were hybrid partridge populations which were caused by releases of chukar partridges in areas where rock partridge has its natural range.

In Epirus and Thessaly pheasant hybrids were established in areas of eight H.C. where their number during spring amounted to 10 - 50 birds and produced a small number of wild pheasants that was harvested each year 
by the hunters. In island H.C. of the North Aegean, chukars were released in areas where a wild population already existed, while in Samos Island about 30 pheasants hybrids were established.

\subsection{Releases for "Put and Take"}

In 2011 the hunting wardens of the Hunting Federation of Macedonia and Thrace were asked about the releases in hunting permitted areas. According to their answers half the clubs made releases in hunting areas (22/44) and the other one half inside the refuges. Pheasant hybrids were mainly released for this purpose in hunting areas (18/31). According to hunting wardens, the majority of birds were killed in $9.7 \pm 1.8$ days, while the number of hunters who were benefited by the harvest of released birds were averaged at $25 \pm 3.2$ hunters in each release.

\subsection{Evaluation According to Wildlife Managers}

In 2014, six wildlife managers of the Hunting Federation of Macedonia and Thrace were asked about the releases that they planned from 2009 until 2014. In 108 releases recorded from the archive of Hunting Federation of Macedonia and Thrace, about 25,000 galliforms were released, 56 releases were conducted for direct harvest (put and take) in hunting permitted areas, 34 releases also for direct harvest but inside hunting prohibited areas (there is a hope that some birds will go out to the permitted area) and 18 releases aiming to population establishment. All the establishment efforts with artificial reared birds failed. Only one establishment effort took place with translocated wild grey partridges and succeeded creating a spring population of about 200 birds. In releases for direct harvest $90 \%$ of birds were killed at $7 \pm 2.3$ days, while hunters who were benefited by the harvest of released birds were averaged at $18 \pm 7.5$ hunters in each release.

\subsection{Economic Evaluation}

According to available data, state farms produced 150,000 galliforms at a cost of about 1,000,000 $€$ (Annual Reports of Forest Operations Services). So the cost of each bird at the stage when it left the farm amounted to $6.7 €$. The corresponding market cost from private farms ranged from 8 to $17 €$ depending on the species and age of birds (Isaac and Kalaitzis, personal communication). The H.C. was obliged to keep galliforms in adaptation enclosures for about one month. The transportation of birds and their conservation in the adaptation enclosures until their release was estimated to raise the mean cost to at least $8 € /$ bird.

The results of this study showed that in central and northern mainland Hellas (Macedonia, Thrace, Epirus, Thessaly), 50 H.C. made releases. On average 400 galliforms were released per H.C. and per year. Thus there were released $50 \times 400=20,000$ birds and the total cost was estimated at 20,000 $\times 8=160,000 € /$ year.

Until 2009 in mainland Hellas releases were allowed only in prohibited areas for hunting. We found that in 38 such areas in central and northern mainland Hellas there were established small groups of galliforms and on average 30 birds were hunted, making a bag of 1140 birds. So 160,000 €/year were spent for a benefit of 1140 harvested birds, thus the minimum cost per harvested galliform until 2009 was $143 €$.

From 2009 to 2014, the number of released birds was decreased to one half, $(10,000 \times 8=80,000 € /$ year $)$, and about one half was released into hunting areas (about 5000 birds/year). If the birds had been released within the hunting season, hunters would had harvested 50\% of birds (Burger, 1964; Sokos et al., 2008), i.e. 2500 birds. But since birds were released several days before the start of the season and inside or by-side of prohibited areas, the losses increased, so it was estimated that hunters harvested at best, one quarter, i.e. 1250 birds. So the overall harvest was estimated at $1250+1140=2810$ galliforms per year (considering that the groups of wild birds remained and produced the same number of 1140 birds). Therefore, the minimum cost per wild galliform after 2009 was reduced to $33.47 €$. Similar estimates can be abbreviated for the cost of chukars harvested in insular Hellas where releases were allowed in hunting areas and before 2009.

\section{Discussion}

The release of galliforms was an action implemented by the majority of H.C. The free supply of birds by the state farms seems to support this policy, although, according to the hunters of Macedonia and Thrace opinions, other management measures than releases, such as the hunting wardening and predator control are more effective to increase the hunting species populations (Sokos et al., 2009).

Most hunting wardens say that even in most successful releases only a small percentage $(1 \%-10 \%)$ of the 
released birds survive for more than three months. This is not surprising, as the survival of artificially reared galliforms in nature is much lower compared to the survival of wild conspecifics (e.g., Leopold et al., 1938; Anderson, 1964). Most birds die in the first weeks after release and less than $10 \%$ can survive for a few months (see the review of Sokos et al., 2008).

The game wardens usually reply that none or very few of the released birds raise chicks. It is known that artificially reared birds that survived and entered in the breeding season have lower reproductive success compared to wild conspecifics (Brittas et al., 1992; Leif, 1994; Putaala \& Hissa, 1998). It has been shown that the main reason that releases fail is the mortality caused by predators, though in many cases, in other countries, predator control is applied. This is attributed to weaknesses of artificial wild galliforms morphology, physiology and behavior (Sokos et al., 2008). In fact, the predator control in Hellas is not applied as it is not permitted by the Forest Service.

However, the repeated releases by the H.C. have led to the establishment of small groups of galliforms in some areas. Usually, there are small groups of birds (10 - 50 birds) in areas where releases are continued. So it cannot be said that in those areas there are established viable populations, because if releases stop, then the few birds will possibly disappear. This was observed in Macedonia where the same game wardens reported that in 2002 had established pheasant hybrids in their area, but the same did not happen in 2011.

It should be noted that usually the release is not conducted together with other management measures such as predator control, habitat improvement and appropriate hunting regulations. Hence, releasing has few probabilities to succeed. It is characteristic that in islands of north Aegean the hunting wardens found that chukars are often established successfully. The opposite happens in mainland according to the hunting wardens' records. This may happen because the abundance of predators in islands may be lower than in mainland Hellas.

In cases of the releases for hunting purposes, the hunting wardens say that the majority of galliforms are killed within a few days after release and that only a few dozens of hunters find and harvest birds. Similarly, Burger (1964) found that of the 5441 artificially reared pheasants released, hunters harvested the $50 \%$ of birds, of which the $80 \%$ was harvested within the first week after release and the $92 \%$ within the third week. According to Burger (1964), the remaining 50\% of birds was killed mostly by predators. Similar results come from other studies too (Thompson et al., 1992; Diefenbach et al., 2000). The low survival and the other disadvantages of direct harvest (put and take) of reared galliforms are reported in the literature (Sokos et al., 2008).

Buechner (1950) supports that the cost of each released galliforms harvested is high because of the low survival after release. In Hellas, according to available data, the minimum cost of galliforms before their release was estimated at $8 € /$ bird, and what finally ended in the hunter's bag cost at least $143 € /$ bird in northern and central mainland Hellas in 2009. In the islands of Hellas and after 2009 in mainland, this amount was reduced to 33.47 €/bird. In Pennsylvania, Diefenbach et al. (2000) found that the released and harvested pheasant's cost was from 22.63 to 90.74 USD/bird. The corresponding cost in Britain was 18 - 33 pounds/bird, while the value of pheasant at the time of release was 2.5 pounds (Robinson, 2000).

\section{Management Implications}

The release of artificially reared galliforms in areas where hunting is prohibited should be limited because these birds are not able for the establishment or strengthening endangered wild populations. Such incorrect practice is being applied for many decades in Hellas causing the wasting of state funds and the money of hunting organizations.

In case of population establishment, translocation of wild birds and alternatively the use of natural or seminatural reared birds are advised (Sokos et al., 2008; Musil \& Connelly, 2009).

The release for direct harvest (put and take) has serious disadvantages, especially in public hunting areas (Sokos et al., 2008). But when that type of release is conducted, the regulation that defines the release to be done at least 30 days before the species' hunting season beginning should be cancelled, due to the low survival of released birds. Instead, we suggest to release up to three days before or during the hunting season, a policy that is expected to reduce the cost per bird that enters the hunter's bag. Moreover, such releases should not taken place inside or by-side hunting prohibited areas, as it was recorded in some cases, because fewer birds will be found by the hunters.

Another problem that was recorded in this study is that galliforms were harvested by a small percentage of hunters, at about $2.5 \%$ to $5 \%$ for H.C. of 1000 to 500 members respectively. The hunter, who will visit the released area, shortly after the release, will harvest the well-paid birds. Therefore, since the hunter does not bear 
the direct costs in public hunting areas, it is recommended: 1) during the hard release operation in the hunting area the birds to be dispersed appropriately, 2) all hunters-members of the H.C. to be informed in the same way for the release operation, and 3) the hunting wardens to protect the hunting area in order to ensure that the harvest limit will be kept. Professional wildlife managers should be responsible for the release operations.

\section{Acknowledgements}

We would like to thank the hunting wardens and wildlife managers of hunting organizations of Macedonia, Thrace, Northern Aegean, Epirus and Thessaly.

\section{References}

Anderson, W. L. (1964). Survival and Reproduction of Pheasants Released in Southern Illinois. Journal of Wildlife Management, 28, 254-264. http://dx.doi.org/10.2307/3798086

Barbanera, F., Guerrini, M., Hadjigerou, P., Panaides, P., Sokos, C., Wilkinson, P., Khan, A., Khan, B., Cappelli, F., \& Dini, F. (2007). Genetic Insight into Mediterranean Chukar (Alectoris chukar, Galliformes) Populations Inferred from Mitochondrial DNA and RAPD Markers. Genetica, 131, 287-298. http://dx.doi.org/10.1007/s10709-006-9138-x

Barilani, M., Bernard-Laurent, A., Mucci, N., Tabarroni, C., Kark, S., Garrido, J. A. P., \& Randi, E. (2007). Hybridisation with Introduced Chukars (Alectoris chukar) Threatens the Gene, Pool Integrity of Native Rock (A. graeca) and Redlegged (A. rufa) Partridge Populations. Biological Conservation, 137, 57-69. http://dx.doi.org/10.1016/j.biocon.2007.01.014

Birtsas, P. K., Sokos, C., Hasanagas, N., \& Billinis, C. (2009). The Hunting Activity in Hellas. Proceedings of VIth International Symposium on Wild Fauna, Organized by Wild Animal Vigilance Euromediterranean Society, Paris, 21-24 May 2009, Extended Abstracts: 52-53.

Brittas, R., Marcstrom, V., Kenward, R. E., \& Karlbom, M. (1992). Survival and Breeding Success of Reared and Wild Ring-Necked Pheasants. Journal of Wildlife Management, 56, 368-376. http://dx.doi.org/10.2307/3808836

Buechner, H. K. (1950). An Evaluation of Restocking with Pen-Reared Bobwhite. Journal of Wildlife Management, 14, 363-377. http://dx.doi.org/10.2307/3797265

Burger, G. V. (1964). Survival of Ring-Necked Pheasants Released on a Wisconsin Shooting Preserve. Journal of Wildlife Management, 28, 711-721. http://dx.doi.org/10.2307/3798786

Diefenbach, D. R., Rienger C. F., \& Hardisky T. S. (2000). Harvest and Reporting Rates of Game-Farm Ring-Necked Pheasants. Wildlife Society Bulletin, 28, 1050-1059.

Gray, C. D., \& Kinnear, P. R. (2012). IBM SPSS Statistics 19 Made Simple. Psychology Press.

Hair, J. F., Black., W. C., Babin, B. J., Anderson, R. E., \& Tattum, R. C. (2006). Multivariate Data Analysis (6th ed.). Upper Saddle River, NJ: Pearson Prentice Hall.

Leif, A. P. (1994). Survival and Reproduction of Wild and Pen-Reared Ring-Necked Pheasant Hens. Journal of Wildlife Management, 58, 501-506. http://dx.doi.org/10.2307/3809322

Leopold, A., Lee, O. S., \& Anderson, H. G. (1938). Wisconsin Pheasant Movement Study, 1936-37. Journal of Wildlife Management, 2, 3-12. http://dx.doi.org/10.2307/3796138

Masseti, M. (1997). Representations of Birds in Minoan Art. International Journal of Osteoarchaeology, 7, 354-363. http://dx.doi.org/10.1002/(SICI)1099-1212(199707/08)7:4<354::AID-OA387>3.0.CO;2-R

Musil, D. D., \& Connelly, J. W. (2009). Survival and Reproduction of Pen-Reared vs translocated wild Pheasants Phasianus colchicus. Wildlife Biology, 15, 80-88. http://dx.doi.org/10.2981/07-049

Pringale, G. (1972). The Hunting in Greece. Analysis of the Problems and Recommendations. UNSF/FAO GRE-20/230, 45 p.

Putaala, A., \& Hissa, R. (1998). Breeding Dispersal and Demography of Wild and Hand-Reared Grey Partridges (Perdix perdix) in Finland. Wildlife Biology, 4, 137-145.

Robinson, P. (2000). Pheasant Shooting in Britain: The Sport and the Industry in the $21^{\text {st }}$ Century. http://www.animalaid.org.uk/images/pdf/kfps.pdf

Sokos, C., Birtsas, P., \& Tsachalidis, E. (2008). The Aims of Galliforms Release and Choice of Techniques. Wildlife Biology, 14, 412-422. http://dx.doi.org/10.2981/0909-6396-14.4.412

Sokos, C., Hasanagas, N., Papaspyropoulos, K., \& Birtsas, P. (2009). Hunting Management and Hunting-Related Values. Proceedings of 2nd Conference on Environmental Management, Engineering, Planning and Economics (CEMEPE 2009), Mykonos Hellas, 21-29 June 2009, 2103-2106.

http://www.panida.gr/site/2011/07/11/hunting-management-and-hunting-related-values/ 
Thompson, J. D., Burger, G. V., Semel, B., \& Ganshirt, C. (1992). Evaluation of the Productivity of Two Strains of Gray Partridge. Poultry Science, 71, 1400-1402. http://dx.doi.org/10.3382/ps.0711400

Viñuela, J., \& Arroyo, B. (2002) Gamebird Hunting and Biodiversity Conservation: Synthesis, Recommendations and Future Research Priorities. Report to EC, Brussels. http://digital.csic.es/handle/10261/8275 